\title{
Yield of screening colonoscopy in renal transplant candidates
}

\author{
Turki AlAmeel MBBS FRCPC FACP ${ }^{1}$, Bahaa Bseiso MD ${ }^{1}$, Meteb M AlBugami MBBS FRCPC FACP2 \\ Sami AIMomen MRCP(UK $)^{1}$, Lee Stuart Roth MD FRCPC DABIM FACP MSC ${ }^{3}$
}

\begin{abstract}
T AlAmeel, B Bseiso, MM AlBugami, S AlMomen, LS Roth. Yield of screening colonoscopy in renal transplant candidates. Can J Gastroenterol Hepatol 2015;29(8):423-426.
\end{abstract}

BACKGROUND: Cardiovascular disease is the most common cause of death among patients with end-stage renal disease undergoing maintenance dialysis. Renal transplantation offers a survival advantage to patients with end-stage renal disease; it is also associated with a three- to fivefold increase in the risk of developing a neoplasm.

OBJECTIVE: To determine the yield of screening colonoscopy among patients with chronic kidney disease who were considered for renal transplantation.

METHODS: Patients were included if they were $\geq 50$ years of age, had chronic kidney disease and were being considered for renal transplantation. They underwent a screening colonoscopy that was performed as part of their pretransplant workup. Data from December 2008 to May 2014 were collected retrospectively for all eligible patients.

RESULTS: During the study period, 433 patients were considered for renal transplantation. Of these, 170 underwent colonoscopies as part of their pretransplant workup. One was excluded because of previous history of colon cancer. Of the 169 procedures performed, $\geq 1$ polyp(s) was diagnosed in $24 \%$. The most common pathological diagnoses were hyperplastic polyp or normal colonic tissue. Fifteen (37\%) patients had tubular adenomas and one patient had a sessile serrated adenoma. Advanced adenomas, defined as villous, tubulovillous or high-grade dysplasia, were found in four patients. Adenocarcinoma was diagnosed in one patient.

CONCLUSION: In a population of asymptomatic potential kidney transplant recipients $\geq 50$ years of age, the prevalence of colorectal adenomatous polyps was $24 \%$. Colonoscopy appeared to be useful as a screening tool in potential transplant recipients.

Key Words: Colonoscopy; Colorectal cancer; Renal transplant; Screening

$\mathrm{R}$ enal transplantation offers a survival advantage to patients with end-stage renal disease (ESRD) compared with maintenance dialysis (1). It is also associated with a three- to fivefold increase in the risk for developing a neoplasm (2). The majority of these malignancies are nonmelanoma skin cancers and lymphoproliferative disorders. The risk of developing colorectal cancer also increases after solid organ transplantation (3). Compared with the general population, the Swedish cancer registries found the incidence of colorectal cancer to be approximately twice as high in transplant recipients (4). In addition, there was a propensity for right-sided cancers, with a standardized incidence ratio of 3.3 versus 1.8 for left-sided colon cancers.

In the general population, screening for colorectal cancer with flexible sigmoidoscopy or colonoscopy has been shown to reduce overall mortality from colorectal cancer. Only colonoscopy was associated with reduced mortality from proximal colorectal cancer (5). In average-risk

\section{Le rendement de la coloscopie de dépistage chez les candidats à la transplantation rénale}

HISTORIQUE : La maladie cardiovasculaire est la principale cause de décès chez les patients atteints d'une néphropathie au stade terminal sous dialyse d'entretien. La transplantation rénale rallonge la survie des patients atteints d'une néphropathie rénale. Toutefois, elle triple le risque de néoplasme, et peut même aller jusqu'à le quintupler.

OBJECTIF : Déterminer le rendement de la coloscopie de dépistage chez les patients atteints d'une néphropathie chronique chez qui une transplantation rénale était envisagée.

MÉTHODOLOGIE : Les patients étaient inclus dans l'étude s'ils avaient au moins 50 ans, s'ils avaient une néphropathie chronique et s'ils étaient évalués en vue d'une transplantation rénale. Ils ont subi une coloscopie de dépistage dans le cadre de leur bilan avant la transplantation. Pour tous les patients admissibles, les chercheurs ont recueilli rétrospectivement les données colligées entre décembre 2008 et mai 2014.

RÉSULTATS : Pendant la période de l'étude, une transplantation rénale a été envisagée chez 433 patients. De ce nombre, 170 ont subi une coloscopie dans le cadre de leur bilan avant la transplantation. Un a été exclu en raison d'antécédents de cancer du côlon. Dans $24 \%$ des 169 interventions effectuées, au moins un polype a été diagnostiqué. Les diagnostics pathologiques les plus courants étaient des polypes hyperplasiques ou des tissus coliques normaux. Quinze patients (37\%) avaient des adénomes tubulaires et un patient, un adénome festonné sessile. On a découvert des adénomes avancés, définis comme des dysplasies villeuses, tubulovilleuses ou de haut grade, chez quatre patients. Un adénocarcinome a été diagnostiqué chez un patient.

CONCLUSION : Dans une population de greffés du rein potentiels et asymptomatiques de 50 ans ou plus, la prévalence de polypes adénomateux colorectaux s'élevait à $24 \%$. La coloscopie semblait utile comme outil de dépistage chez des greffés potentiels.

${ }^{1}$ Division of Gastroenterology; ${ }^{2}$ Multi-Organ Transplant Center, King Fahad Specialist Hospital-Dammam, Dammam, Saudi Arabia; ${ }^{3}$ William Osler Health System, Toronto, Ontario

Correspondence: Dr Lee Stuart Roth, 117-2291 Kipling Avenue, Toronto, Ontario M9W 4L6. Telephone 647-933-9480, fax 416-744-1484, e-mail lroth@tsh.to

Received for publication March 2, 2015. Accepted April 18, 2015 


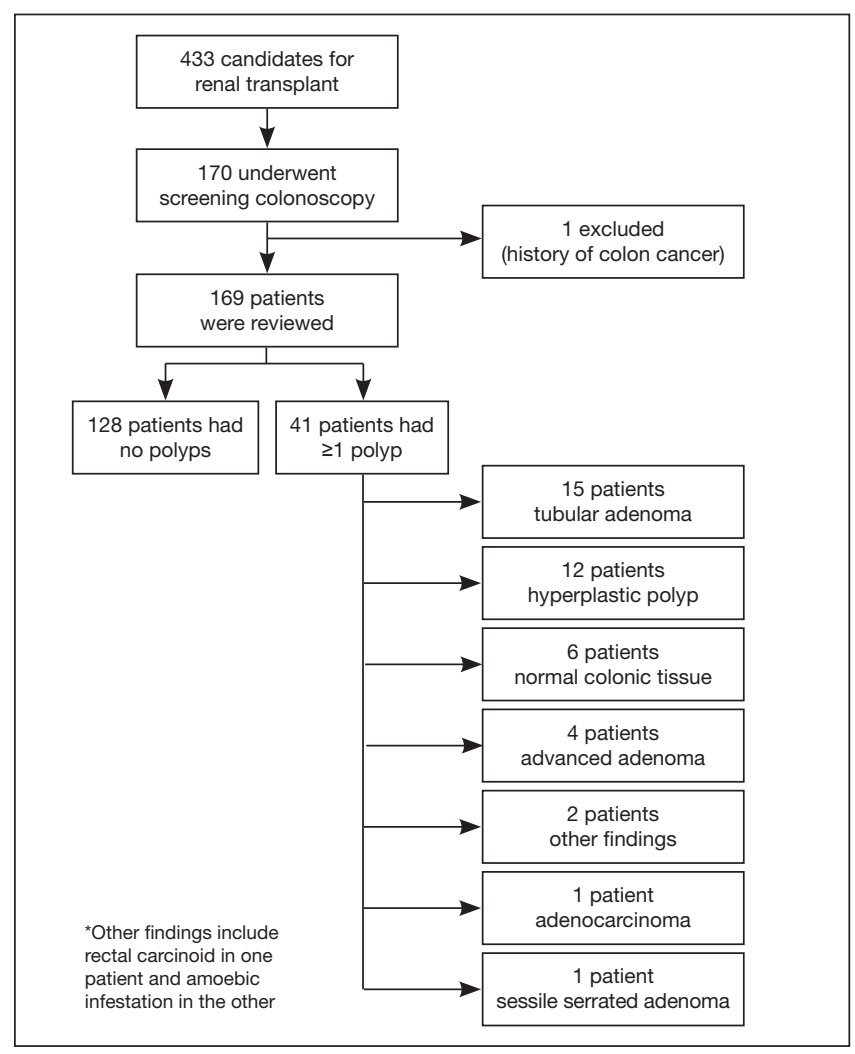

Figure 1) Enrollment and outcomes

patients with chronic kidney disease who were considered for renal transplantation.

\section{METHODS}

Patients were included if they were $\geq 50$ years of age, had chronic kidney disease and were being considered for renal transplantation. Candidates underwent clinical history and physical examination, transthoracic echocardiogram and psychosocial evaluation. They underwent a screening colonoscopy that was performed as part of their pretransplant workup. Patients were excluded if they had a clinical indication for diagnostic colonoscopy such as rectal bleeding, family history of familial adenomatous polyposis or history of colon cancer. A review of patients' medical records, including procedure notes and pathology reports, was performed and data from all eligible patients were retrospectively analyzed. All procedures were performed by nine experienced gastroenterologists who performed $>1000$ colonoscopies before their involvement with the study patients. Patients underwent moderate sedation with propofol or other sedative agents given by an anesthesiologist. Colonoscopies were performed in the endoscopy unit of a tertiary care centre. The study was approved by Institutional Review Board of King Fahad Specialist Hospital, located in Dammam, Saudi Arabia.

\section{RESULTS}

During the study period (September 2008 to May 2014), 433 patients with chronic kidney disease were considered for renal transplantation. The majority of these patients were on peritoneal or hemodialysis by the time they were referred for transplant. In most cases, the etiology of chronic kidney disease could not be identified due to the advanced stage of illness. Of these, 263 were deemed not suitable for transplant after preliminary workup. Reasons for exclusion from transplant included advanced cardiac or pulmonary disease, severe psychiatric illness and poor social support, which can lead to poor post-transplant follow-up. The remaining 170 patients underwent colonoscopy as part of their pretransplant workup. All procedures were completed to the cecum. One patient was excluded due to a history of colon cancer
TABLE 1

Characteristics of the study population

\begin{tabular}{ll}
\hline Age, years, mean (range) & $57.9(50-74)$ \\
Sex, male/female, $\%$ & $61 / 49$ \\
Polyps, n/n total (\%) & $41 / 169(24)$ \\
Advanced adenomas, n/n total (\%) & $4 / 169(2)$ \\
Polyps $>1 \mathrm{~cm}, \mathrm{n} / \mathrm{n}$ total $(\%)$ & $8 / 169(5)$ \\
\hline
\end{tabular}

(Figure 1). The characteristics of the study population are summarized in Table 1 .

Of the 169 procedures performed, 128 revealed no evidence of polyps. Forty-one (24\%) patients had $\geq 1$ polyp(s) diagnosed at the time of colonoscopy. The majority $(n=25[60.9 \%])$ of patients had only one polyp; eight (19.5\%) had two; four $(9.75 \%)$ had three; and $\geq 4$ polyps were found in four $(9.75 \%)$ patients (Figure 2 ). In eight patients, the polyps were estimated to be $>10 \mathrm{~mm}$ in size. The remainder of subjects had subcentimetre size polyps.

The most common pathological diagnosis was tubular adenoma without high-grade dysplasia in $15(37 \%)$ patients. Twelve patients had hyperplastic polyps. In six patients, pathological examination of the removed polyps revealed normal colonic tissue. One patient had a sessile serrated adenoma. Advanced adenoma, defined as villous, tubulovillous or high-grade dysplasia, was found in four patients (Figure 3).

Adenocarcinoma was diagnosed incidentally in one patient. Other findings on pathological examination of resected polyps included rectal carcinoid in one patient and amoebic infestation in another. No complications were reported in the study population.

\section{DISCUSSION}

We found that routine colonoscopy in patients with ESRD considered for renal transplantation with no other clinical indication for colonoscopy resulted in identification of polyps in $24 \%$ of cases. This is similar to the $22 \%$ polyp detection rate found in the general asymptomatic population in Saudi Arabia (11). In our study, one of 169 (0.59\%) patients was found to have adenocarcinoma in the colon.

In patients with ESRD, renal transplantation offers the best treatment. However, the long-term use of immunosuppressive therapy has been associated with increased risk for solid organ tumours (12). Identifying major comorbidities before transplantation may improve overall survival. Early detection of adenomatous polyps may reduce morbidity in post-transplant candidates.

Colorectal cancer is the second leading cause of death due to malignancy. It has an incidence that is two to three times higher in transplant recipients than the general population $(13,14)$. Transplant recipients who develop colorectal cancer are often younger at diagnosis and experience poorer outcomes compared with the general population $(15,16)$.

Colorectal cancer can present relatively early after transplant. In one study investigating 5600 solid organ transplant recipients with mean follow-up of 9.3 years (16), 40 patients developed colorectal cancer. The median time from transplant to cancer diagnosis was 6.6 years and $30 \%$ were diagnosed $<5$ years post-transplant. Screening in renal transplant candidates achieves two important goals: scarce resources will be well utilized; and that transplantation of recipients with active cancer will be avoided to prevent harm (17).

Screening methods for colon cancer can be broadly divided into noninvasive tests and structural examinations. Noninvasive tests include stool testing for fecal occult blood or fecal immunochemical testing, and structural examinations, which can include partial or full examinations of the colon, colonoscopy, flexible sigmoidoscopy and computed tomography colonography (18).

In the general population, the incidence of colorectal cancer was lower among men and women who underwent screening colonoscopy compared with those who had no history of endoscopy. Screening colonoscopy was associated with reduced mortality from both proximal 


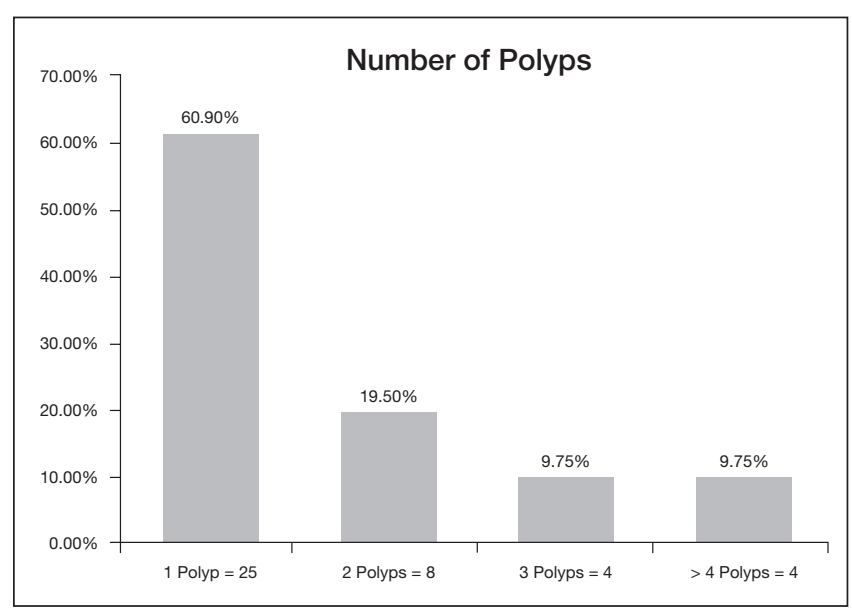

Figure 2) Percentage of patients with $\geq 1$ polyp(s)

and distal colorectal cancer (5). Colonoscopy, however, is not without risks. There is a one in 1000 risk for major complications such as bleeding and perforation. Risk factors for a complication include older age, male sex, polypectomy and having the procedure performed by a lowvolume endoscopist (19). Such complications can lead to significant morbidity, and even mortality, in patients with ESRD.

On the other hand, noninvasive tests have their limitations. In an Australian study investigating the prevalence of colon cancer and advanced adenoma in renal transplant recipients (12), fecal hemoglobin testing had poor sensitivity $(31.0 \%)$ for advanced neoplasia. Nonetheless, the performance of the test was similar to what was found in the general population.

To our knowledge, the present study was the first to investigate the yield of screening colonoscopy in renal transplant candidates. The rate of significant findings, including adenomatous polyps, in our patient population was $13.6 \%$. Other studies examined the yield of colon cancer screening in renal transplant recipients. The prevalence of advanced adenoma or colorectal neoplasia was 13\% (12).

Our study had limitations. All procedures were performed by experienced gastroenterologists, which may have led to a lower complication rate. In a population-based study, nongastroenterologist endoscopists had a higher perforation rate compared with gastroenterologists (20). Lower complication results in our study may also have resulted from having anesthesiologists managing sedation in these patients. Our patients were chosen from a referral centre, which raises the possibility of selection bias. Due to the advanced stage they presented with, we could not identify the underlying cause of their kidney disease.

Renal transplant is an expensive treatment. Adding screening colonoscopy with an anesthesiologist providing sedation to the cost makes it even more expensive. Our study did not address the cost effectiveness of this approach.

On the basis of our results and current recommendations for the general population, we suggest that patients with chronic kidney disease, $\geq 50$ years of age who are at average risk for colon cancer and being considered for renal transplant should undergo a screening test. The choice of screening test, however, should be individualized based on the patient's preference, and the risks and benefits profile of that particular patient.

\section{Current knowledge:}

\section{STUDY HIGHLIGHTS}

- Renal transplantation offers survival advantage to patients with ESRD.

- Screening for colorectal cancer in the general population reduces overall mortality from colorectal cancer.

- Colorectal cancer is the second most common malignancy in transplant recipients.

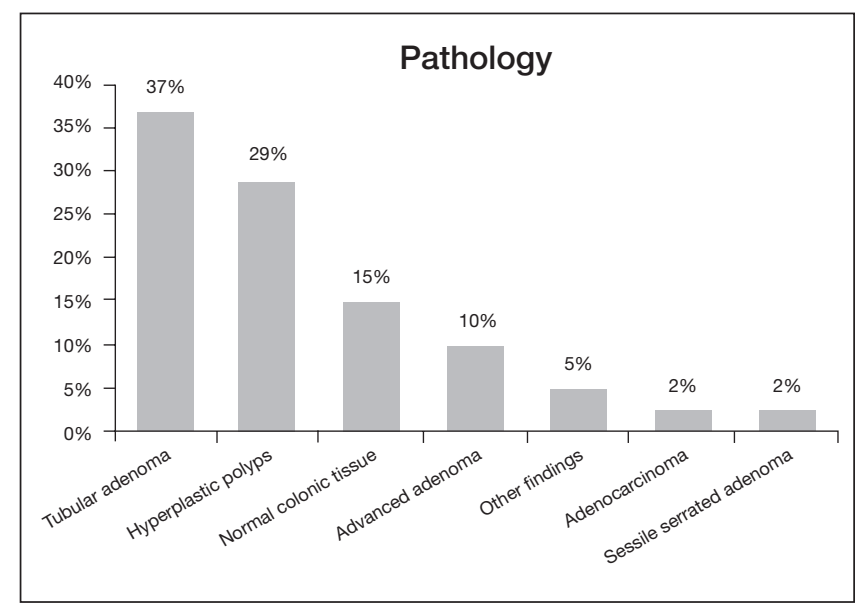

Figure 3) Percentage of different pathological findings

- The yield of screening colonoscopy among patients with chronic kidney disease who were considered for renal transplantation is unknown.

What is new:

- One-quarter of renal transplant candidates had polyps found on screening colonoscopy.

- The rate is similar to what has been reported in the general population.

- The choice of colon cancer screening test in renal transplant candidates should be individualized based on the patient's preference, and the risks and benefits profile.

AUTHOR CONTRIBUTIONS: Turki AlAmeel designed the study, reviewed the literature and drafted the manuscript. Bahaa Bseiso contributed to the design of the study, reviewed the literature, collected the data and contributed to the drafting of the manuscript. Meteb AlBugami contributed to the design of the study, collected the data and reviewed the manuscript. Sami AlMomen contributed to the design of the study and reviewed the manuscript. Lee Roth contributed to the design of the study, performed the statistical analysis and contributed to the drafting of the manuscript.

DISCLOSURES: The authors have no financial disclosures or conflicts of interest to declare.

\section{REFERENCES}

1. Schnuelle P, Lorenz D, Trede M, Van Der Woude FJ. Impact of renal cadaveric transplantation on survival in end-stage renal failure: Evidence for reduced mortality risk compared with hemodialysis during long-term follow-up. J Am Soc Nephrol 1998;9:2135-41.

2. Birkeland SA, Løkkegaard H, Storm HH. Cancer risk in patients on dialysis and after renal transplantation. Lancet 2000;355:1886-7.

3. AlBugami M, Kiberd B. Malignancies: Pre and post transplantation strategies. Transplant Rev (Orlando) 2014;28:76-8.

4. Adami J, Gäbel H, Lindelöf B, et al. Cancer risk following organ transplantation: A nationwide cohort study in Sweden. Br J Cancer 2003;89:1221-7.

5. Nishihara R, Wu K, Lochhead P, et al. Long-term colorectal-cancer incidence and mortality after lower endoscopy. $\mathrm{N}$ Engl J Med 2013;369:1095-105.

6. Levin B, Lieberman DA, McFarland B, et al; American Cancer Society Colorectal Cancer Advisory Group; US Multi-Society Task Force; American College of Radiology Colon Cancer Committee. Screening and surveillance for the early detection of colorectal cancer and adenomatous polyps, 2008: A joint guideline from the 
American Cancer Society, the US Multi-Society Task Force on Colorectal Cancer, and the American College of Radiology. CA Cancer J Clin 2008;58:130-60.

7. U.S. Preventive Services Task Force. Screening for colorectal cancer: U.S. Preventive Services Task Force recommendation statement. Ann Intern Med 2008;149:627-37.

8. Qaseem A, Denberg TD, Hopkins RH Jr, et al; Clinical Guidelines Committee of the American College of Physicians. Screening for colorectal cancer: A guidance statement from the American College of Physicians. Ann Intern Med 2012;156:378-86.

(Erratum in: Ann Intern Med 2012;157:152).

9. Collins AJ, Foley RN, Chavers B, et al. United States Renal Data System 2011 Annual Data Report: Atlas of chronic kidney disease $\&$ end-stage renal disease in the United States. Am J Kidney Dis 2012;59(Suppl 1):A7,e1-420.

10. Holley JL. Screening, diagnosis, and treatment of cancer in longterm dialysis patients. Clin J Am Soc Nephrol 2007;2:604-10.

11. Almadi MA, Alharbi O, Azzam N, Wadera J, Sadaf N, Aljebreen AM. Prevalence and characteristics of colonic polyps and adenomas in 2654 colonoscopies in Saudi Arabia. Saudi J Gastroenterol 2014;20:154-61.

12. Collins MG, Teo E, Cole SR, et al. Screening for colorectal cancer and advanced colorectal neoplasia in kidney transplant recipients: Cross sectional prevalence and diagnostic accuracy study of faecal immunochemical testing for haemoglobin and colonoscopy. BMJ 2012;345:e4657.

13. Vajdic CM, McDonald SP, McCredie MR, et al. Cancer incidence before and after kidney transplantation. JAMA 2006;296:2823-31.
14. Kasiske BL, Snyder JJ, Gilbertson DT, Wang C. Cancer after kidney transplantation in the United States. Am J Transplant 2004:4:905-13.

15. Miao Y, Everly JJ, Gross TG, et al. De novo cancers arising in organ transplant recipients are associated with adverse outcomes compared with the general population. Transplantation 2009;87:1347-59.

16. Johnson EE, Leverson GE, Pirsch JD, Heise CP. A 30-year analysis of colorectal adenocarcinoma in transplant recipients and proposal for altered screening. J Gastrointest Surg 2007;11:272-9.

17. Kiberd BA, Keough-Ryan T, Clase CM. Screening for prostate, breast and colorectal cancer in renal transplant recipients. Am J Transplant 2003;3:619-25.

18. Levin B, Lieberman DA, McFarland B, et al; American Cancer Society Colorectal Cancer Advisory Group; US Multi-Society Task Force; American College of Radiology Colon Cancer Committee. Screening and surveillance for the early detection of colorectal cancer and adenomatous polyps, 2008: A joint guideline from the American Cancer Society, the US Multi-Society Task Force on Colorectal Cancer, and the American College of Radiology. Gastroenterology 2008;134:1570-95.

19. Rabeneck L, Paszat LF, Hilsden RJ, et al. Bleeding and perforation after outpatient colonoscopy and their risk factors in usual clinical practice. Gastroenterology 2008;135:1899-906,1906.e1.

20. Bielawska B, Day AG, Lieberman DA, Hookey LC. Risk factors for early colonoscopic perforation include non-gastroenterologist endoscopists: A multivariable analysis. Clin Gastroenterol Hepatol 2014;12:85-92. 


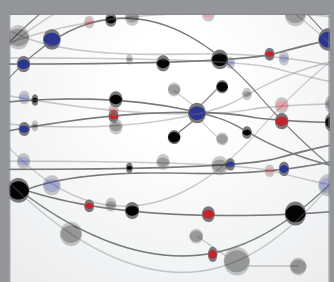

The Scientific World Journal
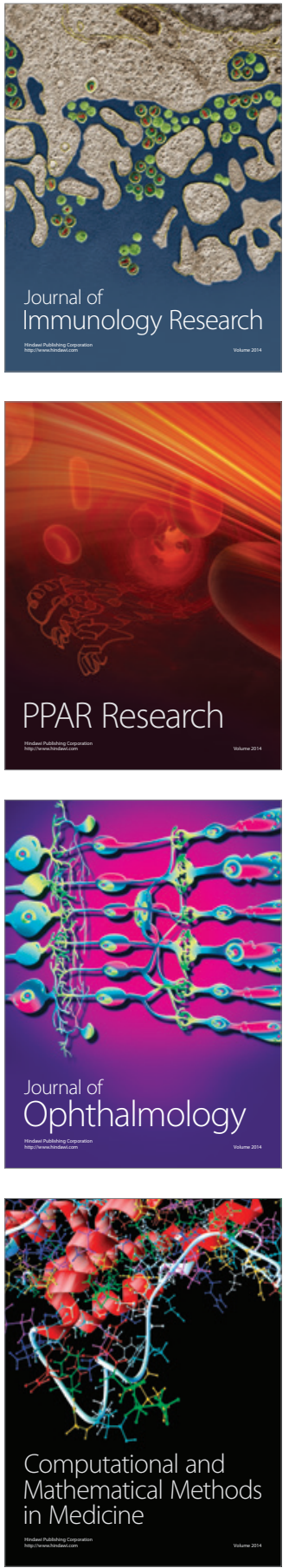

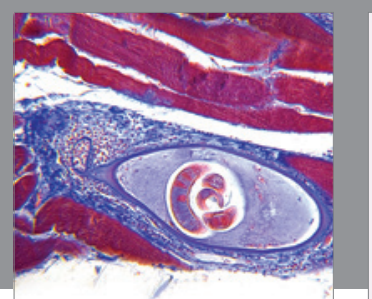

Gastroenterology Research and Practice

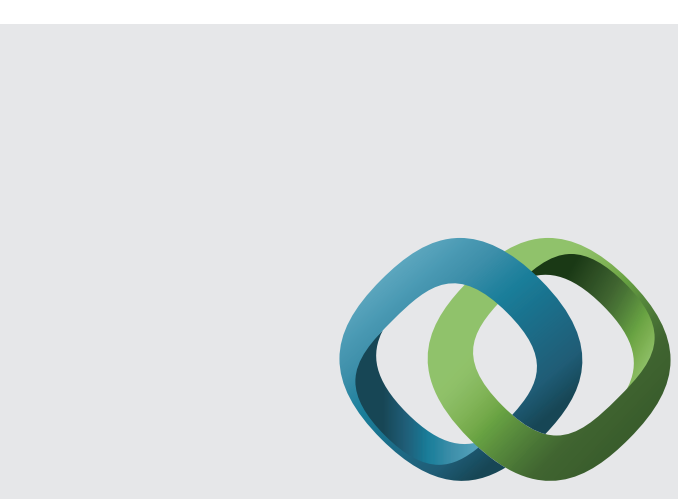

\section{Hindawi}

Submit your manuscripts at

http://www.hindawi.com
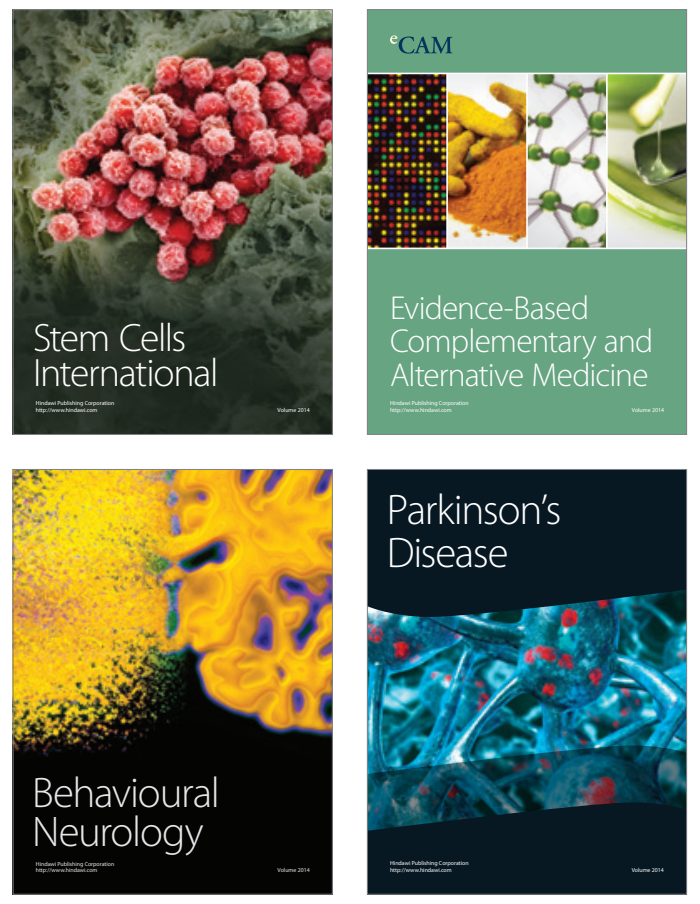
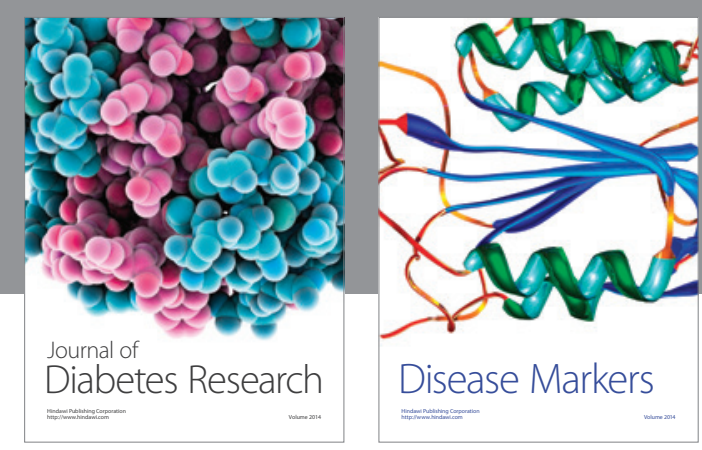

Disease Markers
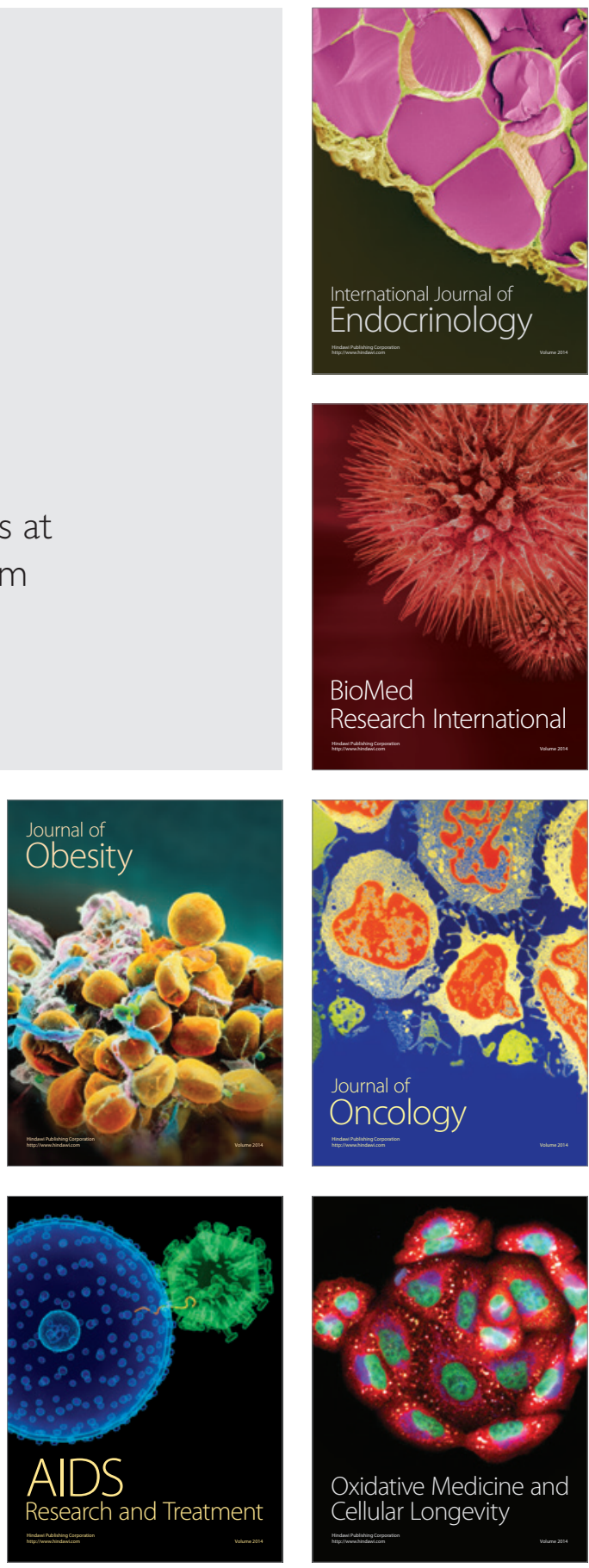